\title{
Future outlook on the materialisation, expectations and implementation of Digital Twins in healthcare
}

\author{
Christel De Maeyer \\ Department of Industrial Design \\ Eindhoven University of Technology \\ c.a.a.d.maeyer@tue.nl
}

\author{
Panos Markopoulos \\ Department of Industrial Design \\ Eindhoven University of Technology \\ p.markopoulos@tue.nl
}

\begin{abstract}
In this paper we examine how experts in digital transformation of healthcare envision the application of Digital Twins. The concept of a Digital Twin refers to a digital replica of potential and actual physical assets, processes, people, places, systems and devices that can be used for various purposes including scientific experiments, simulations and prediction of intervention outcomes. Digital Twins are an emerging technological vision and while evocative as a term it holds different promises and connotations for different application areas and may evolve in very different directions. In order to examine how these directions can develop and impact healthcare we used the Delphi method to reach a consensus among experts on three different research questions we have put forward, namely how experts see the materialisation, expectations and implementation of a Digital Twin in healthcare. Our main conclusion is that Digital Twins are seen as enabling preventive healthcare and trial-and-error approaches to support personalised medicine and/or patient centred care.
\end{abstract}

Digital Twins, personalised healthcare, personal informatics, preventive healthcare

\section{INTRODUCTION}

The concept of a Digital Twin is gaining traction in various fields including medicine, logistics and engineering, in reference to a digital replica of potential and actual physical assets, processes, people, places, systems and devices. These replicas can be used for various purposes, including the analysis of existing situations but also the prediction of intervention outcomes. With the abundance of data available over people's life and daily living the prospect emerges of digital twins in healthcare, which can potentially help understand and diagnose different pathologies, simulate therapies or medical treatments, and predict their outcomes. Such predictions could be made for an individual or a whole population. This prospect is a natural progression from trends in self-tracking technologies and especially the recent increase in digitization of everyday life that has followed the pandemic of covid-19, pertaining to applications for monitoring contagion in forms of contact tracing apps (Rodríguez, 2021), (Lewis, 2021), controlling confinement and social distancing by monitoring the density of cities and regions, using Smart City tools. (World Economic Forum, 2020).
The realization of Digital Twins in healthcare is closely related to the increasing availability of personal health data, as people can easily gather data about themselves, keeping track of different biomarkers, physical activities, and wellbeing in general. Interconnected sensing devices and appliances at home and the workplace enable tracking of an individual's environment and health related behaviours and parameters. Integrated electronic health records provide caregivers and patients easy access to records on vaccinations, medication, and population studies. Scholars are speaking of humans akin to "walking sensor platforms" (Smith, 2016) or "Data selves" (Lupton, 2019). Technically Digital Twins in healthcare require the integration and interoperability of different sources of information, e.g., personal tracking devices and electronic health records. While technically feasible, full integration that could support digital twinning remains a challenge. For example, scholars researching the Quantified Self have been pointing out that the data one gathers with personal devices are not interconnected with each other, there is not really interoperability between all the devices and their accompanied software and by consequence, there is no context surrounding the data (Fuller, 2020), (Elayan, 2021) (Schwartz, 2020). 
Next to technical integration challenges, there are major concerns regarding the protection and security of the data that a Digital Twin might hold, what this data could entail and how its availability may affect healthcare systems and societies at large. Continuous monitoring can lead to datasurveillance, which points to a need for changing health policies and governance: "There should be a major effort to democratizing technology", working on more inclusive policies and regulations (Rasheed, 2020, p. 18), Fukuyama, talks about 'human enhancements' and the potential to create a new class system, "the fear that human enhancement technologies might lead to different classes of people, and therefore have a disruptive effect on our democratic institutions." (Fukuyama, 2002).

Various authors argue how individuals should have autonomy and agency to work with their Digital Twin, "These systems still raise the questions of autonomy and the potential development of nanny technologies which prevent humans from working through their own problems unfettered". (Bartneck, 2020, p. 75). Today, a Digital Twin could be materialized by leveraging data that is already in abundance. It becomes important to assess what the systemic challenges are, pertaining to the realization of digital twins in healthcare: How are we going to use the data? What purposes or expectations are there, and how do we make all the correlations work (Malakuti, 2018)? Can we do this in a safe environment that complies to the guidelines for humane Artificial Intelligence (AI HLEG, 2019)? What are the expectations of a Digital Twin in healthcare and how should we implement a Digital Twin in healthcare?

As Digital Twins are still a future vision, these questions are rather speculative and how they will be resolved depends on the pursuits and sustained efforts of related stakeholders and interest groups. In an attempt to understand the direction in which Digital Twins can evolve, we set out to investigate how stakeholders approach these issues, focusing on three aspects of a Digital Twin in healthcare: their materialisation, the expectations from them and the implementation of a Digital Twin in healthcare especially considering ethics. We report on a Delphi study with a panel of experts $(\mathrm{N}=9)$ from the healthcare sector in Belgium, which was conducted between July-October 2020. Our study included three rounds of questions as above on the materialisation, expectations, and implementation of a Digital Twin in healthcare systems.

The Delphi study that we report in the following sections of this concluded that a) Implementing Digital Twins in healthcare can bring value mostly in relation to short clinical trials on Digital Twins b) Experts expect that Digital Twins will give way to personalised medicine for patients c) Implementation in healthcare requires including a human in the loop for all decision making and usage of the Digital Twin.

In the remainder of the paper, we briefly overview the state of the art regarding Digital Twins in healthcare and we elaborate on the aims of this research the Delphi methodology we followed and our findings.

\section{WHAT ARE DIGITAL TWINS?}

A Digital Twin refers to a digital replica of potential and actual physical assets (physical twin), processes, people, places, systems, and devices that can be used for various purposes (Grieves M. , 2014). A virtual representation of a physical object holds a lot of detail and is a rich representation of the physical object, almost indistinguishable from the original (Grieves M. , 2014). The concept of a Digital Twin was introduced in 2003, at the University of Michigan during a course on Product Lifecycle Management as a tool or a system for tracking and documenting the process from the production of raw materials all the way to finished products. The automation of production, enables collecting a wealth of data from production lines, giving insights on the design and maintenance of a physical product, using disparate data sources, such as physical non-destructive sensing technologies, including sensors and gauges, lasers and so forth. The notion of a Digital Twin concept that could illustrate a physical object and its detailed underlying information to come to a closed production loop, could thus give an overview on its production cycle, enable optimization and a more cost-effective production line (Grieves M. , 2014).

A Digital Twin must fulfil three prerequisites: first one needs a physical object or asset that we want to twin, second, one needs a virtual version of the physical object and third one needs to establish and maintain the connections between the physical and virtual object through data collection bringing everything together in the virtual representation. The virtual side of a Digital Twin allows testing and/or simulating, emulating, and mirroring different situations before these are applied upon the physical object or entity. This enables the assessment of consequences before an actual situation occurs. In health-related applications this offers the possibility to forecast and/or predict the outcome of certain medical treatments and even to personalize them towards the patient. As mentioned in the white paper by Grieves (Grieves M. , 2014), one could have 'lightweight versions' of a virtual model. This allows physicians to look at different characteristics of the patient and isolate different pathologies to monitor and control for a certain patient, considering the different aspects and 


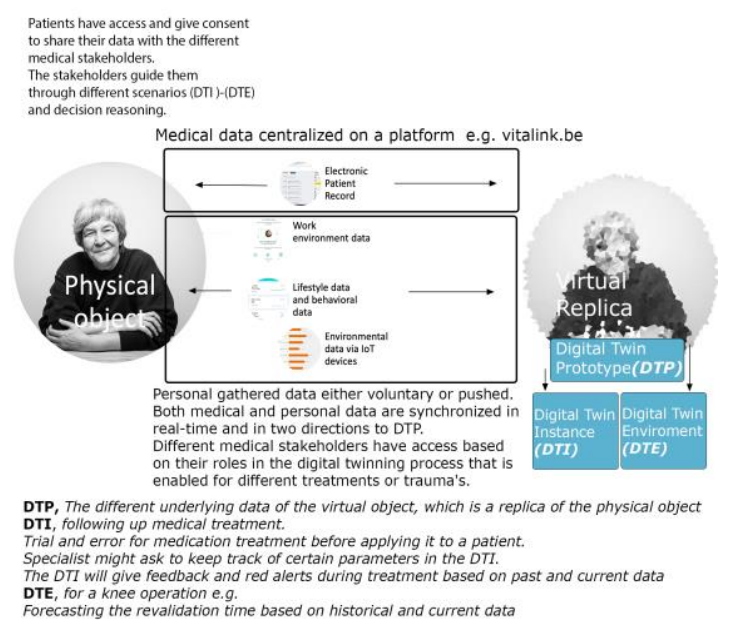

Figure 1: Visualization Digital Twin concept

characteristics of a human being as seen in figure 1. At a systemic level Digital Twins can potentially facilitate a transition towards a more care oriented medical approach instead of the cure approach we have today. 'A Digital Twin is meant to be a living, intelligent and evolving model depending on data and information it gets from the physical counterpart' (Barricelli, 2019, p. 167656). The actual Digital Twinning process is possible because of the continuous synchronization, communication and interaction between the physical entity and its virtual replica, a 'closed-loop optimization' as it were. Foremost because the affordance of exchanging real-time data between the physical object and its virtual counterpart and the capability of big data storage nowadays (Barricelli, 2019). However, to get more clarity on the different manifestations of a Digital Twin, Grieves (Grieves M. V., 2017) elaborates the definitions of the different manifestations of a Digital Twin. The first definition we discussed above is the general definition of a Digital Twin (DT or DTP). The different manifestations of a Digital Twin exist of two types: a Digital Twin Instance (DTI) and a Digital Twin Environment (DTE) as shown in figure1.

As shown in the visual above, a 'Digital Twin prototype (DTP)' holds the necessary information to model a twin or virtual version of the physical object. The Digital Twin prototype holds information of the physical object. In the case of healthcare, data gathered by patients and different stakeholders (EPR, lifestyle and environmental data), the data is annotated and comes with a set of requirements together with a bill of materials to use a Digital Twin and how to apply different possible scenarios as we will see further on in this paper, e.g., short clinical trials, which will be launched on a Digital Twin instead of on a patient. In addition, there is a bill of disposal connected to the Digital Twin prototype, in the case of healthcare these bills are regulated by the government in most cases, e.g., when a patient dies the Digital Twin might be archived for $x$ years, or patients can give consent to use it for future research.

A Digital Twin Instance (DTI) allows for interrogation and trial and error testing on the DTP. For example, depending on certain scenarios and use cases, surgeons could simulate a knee operation and forecast the revalidation time a patient will need to recover looking at the medical and lifestyle data (historical and current data) of that patient. In addition, there is the Digital Twin Environment (DTE). This is a multi-domain physics application space for operating on Digital Twins that allows for prediction of future behaviour and performance of the physical object, in our case the human (Grieves M. V., 2017, p. 94).

\subsection{Digital Twin in healthcare}

The notion of a Digital Twin in healthcare refers to idea that we have a digital replica of a human being, that will adapt in real-time to the data that nurtures it. As people accumulate data about themselves in different settings through sensory devices in their home environment, biomarkers delivered by wearable devices and medical data that is digitized in hospitals, deep learning techniques can be used to analyse lifestyle patterns, one can monitor the positive and negative consequences of a certain lifestyle, spot risks or anomalies before they arise. Contextual data such as emotional states, environmental data, age and preferences can potentially enable holistic considerations of individuals (Fuller, 2020), (Saddik, 2018). Even though they are still at an early stage, we see already commodity applications that monitor biomarkers of individuals. Applications such as Fibricheck (Fibricheck, sd), for remote heart rhythm monitoring are medically approved and have been used in clinical trials, for prevention purposes or as (remote) following up after therapy.

Another notable application that can be thought of as an early example of a Digital Twin, is Epicare@home (Byteflies, sd), which is a personalised wearable allowing seizure monitoring. Epicare@home bridges between the home of the patient and the hospital. Clinical data is collected by the patient in the comfort of their home through the wearable and shared with the neurologist. Epicare@home enables personalised treatments for epilepsy patients.

Remote surgery is another potential application area, where surgeons could remotely plan and simulate a surgery, minimizing risks on life. 'In the future the patient and the surgeon might also possess their own Digital Twin which would enable the system to read historical data and real time health and performance data. This leads us to a situation where several Digital Twins are brought 
together into one in order to accomplish a task. The Digital Twins needs to be fired up to bring all the required agents together. This means that Digital Twins will be born and terminated in relation to specific events, which further magnifies the security issues mentioned before' (Lakki, 2019, p. 20334), (Barricelli, 2019).

\section{A DELPHI STUDY ON THE FUTURE OF DIGITAL TWINS IN HEALTHCARE}

The realization of a Digital Twin is a process that requires the synergy of diverse stakeholders in different sectors, who need to align their efforts to overcome diverse technological, business, and societal challenges. To gauge the challenges and opportunities ahead and how best to approach the vision of the Digital Twins in healthcare, we set out to solicit and synthesize the views from experts active in this area. We set up a panel of Belgian experts in digital technology for healthcare, to examine the materialisation, expectations, and implementation of Digital Twins in healthcare, considering the ethical guidelines that are in place for Al systems, as these have been defined by EU experts (AI HLEG, 2019). Anticipating that experts approach the concept of Digital Twins from different angles, we sought a method to help solicit a consensus view from them. We used the Delphi research method (Helmer, 1950-60) to structure our inquiry and come to a consensus on aforementioned topics.

\subsection{The Delphi method}

The Delphi method is a structured approach for soliciting and combining input from experts in pursuit of a consensus view (Renzi, 2015; Yang, 2019). In this method the panel is assembled purposefully, to include a diversity of experts who can provide sufficient variety of insights and viewpoints. Further, The Delphi method allows for three types of questions where different expertise and experts are needed (Gordon, 1994):

- Forecast the occurrence of future developments. For example, 'the future of virtual agents in healthcare'

- Desirability of a certain development. For example, 'designing designer babies with CRIPR technology'

- The means for achieving or avoiding a future state. Involves policies concerning implementations. The who, what and when and where, needs to be tight to the objectives sought and the likelihood that a policy will accomplish its goals. For

\footnotetext{
${ }^{1}$ https://www.youtube.com/watch?v=oQh8ugLWrpU
}

example, 'how to define policies for mass surveillance mechanisms'

The Delphi methodology may combine different methods for questioning the expert panel, both qualitative and quantitative methods, such as indepth interviews, group interviews or online surveys. Experts remain anonymous to each other to allow them to evaluate each other's opinions free from social desirability bias. Researchers are tasked with surveying opinions, collecting, and organizing them to facilitate voting, aiming to converge at a consensus view. The method involves surveying opinions, pooling them together and iterative steps of ranking, and rating these opinions to reach a consensus among the participants. To avoid biases relating to group influences, there are no discussions among the participants during the iterative process of this method.

Over the years digital media have been increasingly applied in Delphi studies to share contributions efficiently, to ensure anonymity of input or even the asynchronous execution of Delphi studies using various groupware.

\subsection{Participants}

We applied purposive sampling, to form a panel of experts with knowledge and expertise regarding future healthcare, in different domains that are interconnected with each other. We received a list of experts that collaborate with the government, and more specifically with the department of Economy, Innovation and Science, as this department is also responsible for innovation funding and setting up innovation hubs in Belgium, fostering triple helix collaborations (Etzkowitz, 2017). From that list we chose our experts (N9) and recruited from researcher's own network. A typical Delphi panel has about 8 to 12 members, other sizes are possible but a minimal of 7 is advised to avoid deteriorate accuracy. (Mullen, 2003)

Each candidate received a recruiting mail, and an intake conversation was done with each expert. There were no dropouts during this research and panel experts didn't have contact with each other.

\subsection{Materials}

The Qualtrics software was used through the entire project, except for Q1 was done in Google forms.

To kick off the study, and to create a common frame of reference for the experts, we started with viewing a publicly available and widely disseminated explanation video ${ }^{1}$ of a TEDX talk, a local independent conference based on TED conference format, featuring a talk by Jacqueline Alderson, Associate Professor, at Auckland University of 
Technology introducing the concept of Digital Twins. The video was chosen because it captures an academic perspective and is more neutral when compared to related corporate vision videos that represent a specific business interest. The video served as a preamble for the first question to the panel regarding the materialisation of a Digital Twins in healthcare.

Below we elaborate on the setup of the questionnaire and the schedule or timing of the different questions on the materialisation, expectation, and implementation of a Digital Twin in healthcare.

Table 1: Overview of experts

\begin{tabular}{|c|c|}
\hline Disciplines or skills & Organizations \\
\hline $\begin{array}{l}\text { Health Tech and Bio Tech } \\
\text { engineering. Guidance for } \\
\text { health tech start-ups. } \\
\text { Academic research in the } \\
\text { domain of healthcare, IT } \\
\text { managerial tasks in } \\
\text { University Hospital }\end{array}$ & $\begin{array}{l}\text { Innovation Hub with foci on } \\
\text { digital healthcare } \\
\text { transformation ( } 2 \text { experts) } \\
\text { (Academic and Industrial } \\
\text { appointment) }\end{array}$ \\
\hline $\begin{array}{l}\text { Bioengineer, passion for } \\
\text { health and health care and a } \\
\text { sweet spot for science }\end{array}$ & $\begin{array}{l}\text { Health House, with focus } \\
\text { on the future of healthcare } \\
\text { based on scientifically } \\
\text { validated content and the } \\
\text { impact technology will have } \\
\text { on this future. } \\
\text { (Academic and Industrial } \\
\text { appointment) }\end{array}$ \\
\hline $\begin{array}{l}\text { Exec in Biotech companies, } \\
\text { academic cancer, omics and } \\
\text { digital health adoption } \\
\text { research, CEO Digital health } \\
\text { agency, cochair Digital Twin } \\
\text { Consortium }\end{array}$ & $\begin{array}{l}\text { Healthcare futurist } \\
\text { Academic and (Industrial } \\
\text { appointment) }\end{array}$ \\
\hline $\begin{array}{l}\text { CEO of a private retirement } \\
\text { home. Today guidance in } \\
\text { health tech start-ups }\end{array}$ & $\begin{array}{l}\text { Retirement home and start- } \\
\text { up guidance in health tech } \\
\text { (Industry) }\end{array}$ \\
\hline $\begin{array}{l}\text { Strategic and policy vision of } \\
\text { the continuum of life, cure, } \\
\text { care, comfort \& wellbeing }\end{array}$ & $\begin{array}{l}\text { Caregiving implementor, } \\
\text { platform for caregivers } \\
\text { (Industry) }\end{array}$ \\
\hline $\begin{array}{l}\text { Creative \& strategical } \\
\text { marketing \& communication } \\
\text { agency for the silver market }\end{array}$ & $\begin{array}{l}\text { Marketing Bureau for } \\
\text { seniors } \\
\text { (Industry) }\end{array}$ \\
\hline $\begin{array}{l}\text { Product management with } \\
\text { demonstrated history of } \\
\text { working in healthcare }\end{array}$ & $\begin{array}{l}\text { Medical Imaging and } \\
\text { workflows } \\
\text { (Industry) }\end{array}$ \\
\hline $\begin{array}{l}\text { Specialized in digital } \\
\text { transformation (international } \\
\text { and national) }\end{array}$ & $\begin{array}{l}\text { Caregiving implementor for } \\
\text { caregivers and patients } \\
\text { (Industry) }\end{array}$ \\
\hline
\end{tabular}

\subsection{Procedure}

After selecting the experts, we launched a cycle of the three iterations we were interested in, each addressing one of the main research questions. The research questions were developed based on the existing literature in the area of Digital Twins in healthcare with a focus on 'Forecast on the occurrence of future developments' (Gordon, 1994).

1. How do you see the materialisation of a Digital Twin in healthcare?

a. Experts gave their ideas and thoughts on the materialisation of a Digital Twin in healthcare.

b. The input was synthesized and ranked by importance.

c. Kendall's W was used to measure the agreement and consensus of Q1.

d. We selected the top three ranked items and asked the participants to rate their agreement to the items on a 7-point Likert scale (1- strongly disagree to 7strongly agree). This step was implemented to get a focused and prioritized view of experts on all the concepts that were mentioned in relation to the materialisation of a Digital Twin.

2. What are the expectations of a Digital Twin in healthcare?

a. Experts received a list of expectations based on EU guidelines, 'from fundamental rights to ethical guidelines' (AI HLEG, 2019, p. 10).

b. From the input list, experts were asked to rate the input list according to desirability on a Likert scale (1 undesirable - 5 extremely desirable)

c. This list was then ranked to come to Top 3.

3. How do you see the implementation of a Digital Twin in healthcare?

a. Experts gave their ideas and thoughts on the implementation of a Digital Twin in healthcare.

b. The synthesized input list was then ranked by importance by the experts.

c. Kendall's W was used to measure the agreement and consensus of Q3.

d. After ranking the synthesized input list, experts were asked to rate the Top 3. 


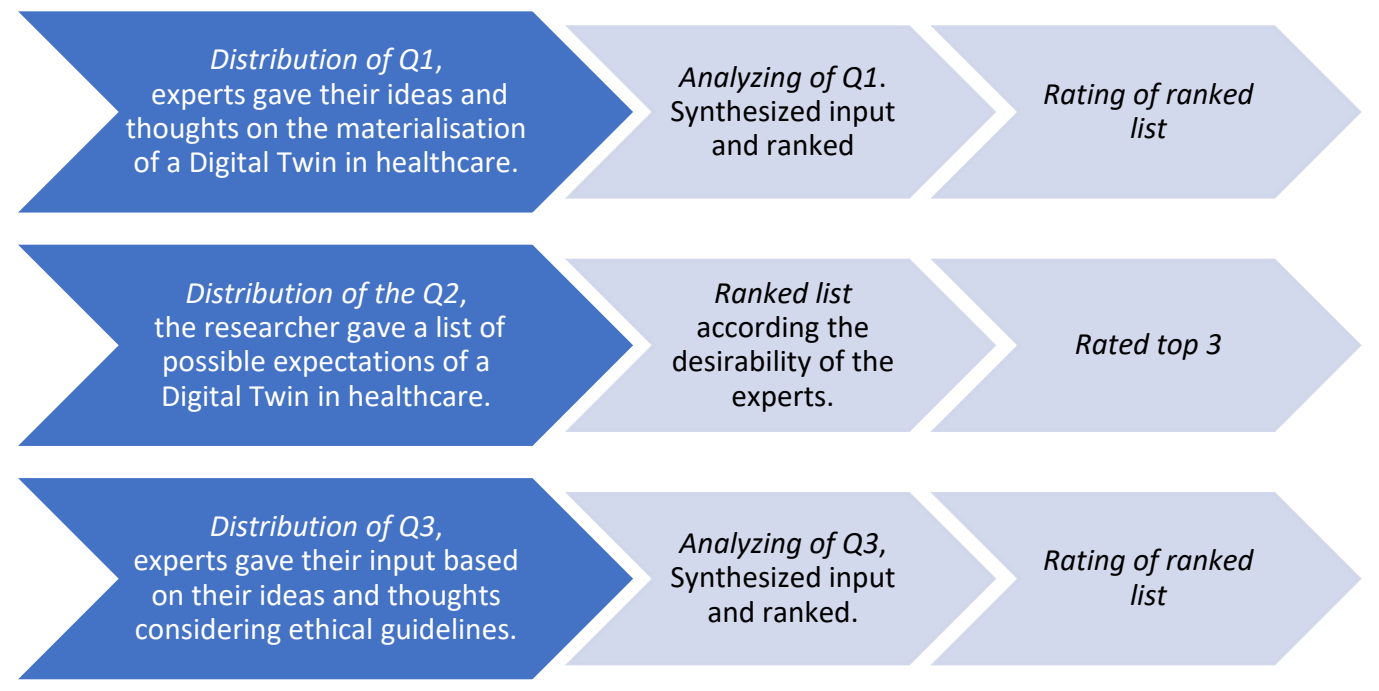

Figure 2: Setup of the distribution of the questionnaire using the Delphi method

\subsection{Timeline of study}

Table 2: Timeline of distribution research questions

\begin{tabular}{|c|l|}
\hline June & \multicolumn{1}{c|}{ Recruiting of experts } \\
\hline 7.7 .2020 & $\begin{array}{l}\text { First research question - Listing by } \\
\text { experts, the materialisation of a Digital } \\
\text { Twin in healthcare. }\end{array}$ \\
\hline 22.8 .2020 & $\begin{array}{l}\text { Ranking of synthesized input first } \\
\text { question }\end{array}$ \\
\hline 10.9 .2020 & $\begin{array}{l}\text { Rating of the ranking first question (top } \\
\text { 3). }\end{array}$ \\
\hline 10.9 .2020 & $\begin{array}{l}\text { Ranking of second question (input given } \\
\text { by the researcher), the expectations of } \\
\text { a Digital Twin in healthcare. }\end{array}$ \\
\hline 21.9 .2020 & $\begin{array}{l}\text { Rating of input on second question (top } \\
\text { 3) }\end{array}$ \\
\hline 27.9 .2020 & $\begin{array}{l}\text { Third research question - listing by } \\
\text { expert, the implementation, considering } \\
\text { ethical guidelines of a Digital Twin in } \\
\text { healthcare. }\end{array}$ \\
\hline 11.10 .2020 & Ranking of the input on third question. \\
\hline 19.10 .2020 & Rating on the third question (top 3) \\
\hline 20.10 .2020 & Closing \\
\hline
\end{tabular}

\section{RESULTS}

\subsection{Q1. How do you see the materialisation of a Digital Twin?}

Experts were asked to fill in their thoughts and ideas on the materialisation of a Digital Twin in healthcare. Overall, the answers to this question went in the direction of preventive care and shifting the focus of healthcare on care rather than cure. Experts suggested the notion that a Digital Twin could be an environment used for trial and error of different interventions, based on historical and current data of a patient. Furthermore, on a macro level Digital Twins could be used to reorganize our healthcare system as we know it. In terms of health insurance, it could create a health index of a certain population. At a micro level, Digital Twins could lead towards more precise and personalised medicine.

By grouping and collapsing similar ideas and rephrasing them in a consistent way, we composed a list of 11 concepts regarding the possible promise of Digital Twin. In round two we asked experts to rank the items of this list (1 is most important, 11 is least important). The items and their average ranking are shown in table 3.

Table 3: Topics Ranked Order of materialisation of Digital Twin

\begin{tabular}{|l|c|}
\hline & M (STD) \\
\hline $\begin{array}{l}\text { Digital Twin as a concept for trial and error in } \\
\text { healthcare instead of operating trial and error } \\
\text { directly on patients. }\end{array}$ & 2.56 (2.27) \\
\hline $\begin{array}{l}\text { Digital Twins as facilitators towards } \\
\text { preventive healthcare }\end{array}$ & 2.56 (0.96) \\
\hline $\begin{array}{l}\text { Digital Twin in Intensive Care Units where } \\
\text { patients are followed in detail, based on } \\
\text { certain parameters (controlled lab } \\
\text { environment) might be a good starting point }\end{array}$ & 4.44 (2.91) \\
\hline $\begin{array}{l}\text { Digital Twin with a focus on (a) certain } \\
\text { parameter(s) within a controlled environment } \\
\text { for now. }\end{array}$ & 5.33 (1.83) \\
\hline $\begin{array}{l}\text { Digital Twin as 24/7 personal assistant where } \\
\text { the whole chain of family, healthcare givers } \\
\text { and trusted network can follow the journey of } \\
\text { a patient or ageing person. }\end{array}$ & \\
\hline $\begin{array}{l}\text { Digital Twin will help with effective care } \\
\text { interventions }\end{array}$ & 4.78 (1.81) \\
\hline Digital Twins as facilitator towards longevity & $7.22(2.35)$ \\
\hline $\begin{array}{l}\text { Digital Twin could have potential to save } \\
\text { money on our healthcare in general but also } \\
\text { towards the patient (patients who are really } \\
\text { taking care of themselves should be } \\
\text { rewarded), those who are not complying will } \\
\text { have to pay more for insurance or } \\
\text { consultations. }\end{array}$ & \\
\hline
\end{tabular}




\begin{tabular}{|l|l|}
\hline $\begin{array}{l}\text { Digital Twin as a prevention healthcare } \\
\text { based on a health index. Linked to our social } \\
\text { healthcare system (insurance) }\end{array}$ & $7.67(2.45)$ \\
\hline Digital Twins could avoid loneliness, solitude & $8.67(2.45)$ \\
\hline $\begin{array}{l}\text { Digital Twin as prevention maintenance is } \\
\text { still far away }\end{array}$ & $9.56(1.77)$ \\
\hline
\end{tabular}

Kendall's W coefficient of concordance was applied to verify the agreement level of the ranking process. The level of agreement of the list was low. Kendall's $W=0.493$, though significant $(p=0,000)$. Examination of the data showed that few ideas were aligned with the experts.

We selected the top three ranked responses and asked them to rate their importance, leading to a slight reordering, as presented in Table 4, compared to the original ranking of the full collection of items.

Table 4: Importance ratings for the three top ranked items from $Q 1$ regarding the materialisation of a Digital Twin Likert-scale (1- strongly disagree to 5- strongly agree)

\begin{tabular}{|l|c|}
\hline & M (STD) \\
\hline $\begin{array}{l}\text { Digital Twin as facilitator towards preventive } \\
\text { healthcare }\end{array}$ & $4.33(0.47)$ \\
\hline $\begin{array}{l}\text { Digital Twin in intensive care units where } \\
\text { patients are followed in detail, based on } \\
\text { certain parameters (controlled lab }\end{array}$ & $3.89(0.74)$ \\
environment) might be a good starting point) & \\
\hline $\begin{array}{l}\text { Digital Twin as a concept for trial and error in } \\
\text { healthcare instead of operating trial and error } \\
\text { directly on patients }\end{array}$ & \\
\hline
\end{tabular}

Regarding prevention, a Digital Twin could create more awareness with individuals based on the bioand lifestyle feedback, individuals could adjust their behaviour if needed. Furthermore, Digital Twins could give the ability to forecast certain scenarios in life. Such scenarios have been discussed before in the context of quantified self-applications, for example, a marathon runner, who prepares for marathons together with his sports doctor; the doctor advises which diets to follow, which exercises are good to prepare to avoid injuries based on past data and current lifestyle of the marathon runner (De Maeyer, 2020), (Bagaria, 2020). Another application scholars foresee, is simulating side effects of certain drugs/medication (Fuller, 2020), (Bruynseels, 2018).

As one of the experts stated 'Prevention: it would be fantastic if, in addition to a health index, your Digital Twin would also provide certain risk scores for certain chronic diseases and the course of those scores over time'.

The second most promising idea for experts, concerns the notion of Digital Twins used in intensive care as a controlled environment to follow patients very closely based on certain/specific parameters. As one of the experts wrote: 'the state of the art "Digital Twin" environment is an ICU in which patients (in a sick context) are optimally and continuously monitored based on numerous parameters. However, this is a perfectly controlled environment, it seems interesting to us to start from there in order to gain ideas that you can translate to a healthy population (including healthy elderly people)'.

The third rated idea concerned the notion of trialand-error, a mechanism that can be applied on the Digital Twin replica of the patient before applying clinical trials to a certain patient. These trial-anderror mechanisms that could be applied to a Digital Twin could evolve towards personalised medicine or human (patient)-centred healthcare (Rasheed, 2020), (Searl, 2010). Clinical trials could be done on 'Lightweight versions of the virtual model which exist on a temporary basis for these tests for example (Grieves M. , 2014), as we see in the applications of Fibricheck or Epicare@home.

\subsection{Q2 What are the expectations of a Digital Twin, input given by researcher}

The expectations from Digital Twins in healthcare as discussed in the EU guidelines, (AI HLEG, 2019) were rated for their desirability in two steps. First experts each provided their rating of desirability. The list is shown in table 5 ordered from the most to the least desirable. Then we asked experts again to rate the top three items; the ratings are shown in table 6.

Table 5: Ratings of desirability on Q2 What are the expectations of a Digital Twin? Likert-scale (1undesirable to 5-extremely desirable)

\begin{tabular}{|l|l|}
\hline & M (STD) \\
\hline $\begin{array}{l}\text { Getting insights on remedial process for a } \\
\text { specific patient (personalised medicine) }\end{array}$ & $4.44(0.50)$ \\
\hline $\begin{array}{l}\text { Getting context around the data to do a more } \\
\text { accurate assessment and support decision } \\
\text { making. }\end{array}$ & $4.33(0.47)$ \\
\hline $\begin{array}{l}\text { Getting oversight on the health status of a } \\
\text { population }\end{array}$ & $3.63(0.48)$ \\
\hline $\begin{array}{l}\text { Getting insights in a longitudinal data-driven } \\
\text { lifecycle of individuals }\end{array}$ & $3.56(0.83)$ \\
\hline $\begin{array}{l}\text { Getting insights in vulnerable groups, pro- } \\
\text { active remediation towards a more equal } \\
\text { society? }\end{array}$ & $3.25(0.43)$ \\
\hline $\begin{array}{l}\text { Digital Twins in healthcare will be an on- } \\
\text { demand service for individuals? }\end{array}$ & $3.13(0.60)$ \\
\hline $\begin{array}{l}\text { Health insurance will be reinvented, they will } \\
\text { work with Health KPl's which are parameters } \\
\text { for your insurance }\end{array}$ & $3.00(1.00)$ \\
\hline
\end{tabular}

Table 6: Ranked top 3 on the question 'What are the expectations of a Digital Twin'? According to desirability

\begin{tabular}{|l|c|}
\hline & M (STD) \\
\hline $\begin{array}{l}\text { Getting insights on remedial process for a } \\
\text { specific patient (personalised medicine) }\end{array}$ & $1.86(0.64)$ \\
\hline $\begin{array}{l}\text { Getting context around the data to do a more } \\
\text { accurate assessment and support decision } \\
\text { making. }\end{array}$ & $2.00(0.93)$ \\
\hline
\end{tabular}


Getting oversight on the health status of a population

Regarding the top 3 expectations of a Digital Twin in healthcare, we see that 'Getting insights on remedial process for a specific patient (personalised medicine)' is connected to the last aspect of materialisation of a Digital Twin. The trial and error on a Digital Twin could lead way and give insight as well on a 'remedial process' for a specific patient, hence leading towards 'personalised medicine'.

The second expectation 'Getting context around the data to do a more accurate assessment and support decision making'. One of the expert's input: 'These data are for individual use (each user is unique), collected anonymously so that new connections can be discovered via machine learning, and the care is further optimized compared to what is known today (both medicinal and non-medicinal). In the long term I see that dashboard as a little less static but effective as a virtual replica of the user where data 'flows' through that virtual body in real-time or nearreal time. The timeframe can then be moved or stretched via a slider, so that the evolution over time of a specific parameter becomes visible'. The interoperability of the data silos that are there today, will become extremely important to create context around data- driven healthcare if one wants to use the context to support decision making and get more accurate data-driven information (Barricelli, 2019), (Rivera, 2019). Indeed, the last rated expectation could give a health status on a certain or given population. The pitfalls here are the biases that are generated within a data-driven model. There needs to be attention to these biases as they can lead to new health policies, exclude or include a certain privileged or underprivileged population (O' Neill, 2016). This connects directly to the next research question concerning the implementation of a Digital Twin, considering ethical guidelines set out by an expert group on EU level.

\subsection{Q3 How do you see the implementation of ethically guidelines?}

Experts gave their opinions and thoughts regarding the implementation of ethical guidelines. These thoughts were then shared anonymously between experts who rank ordered them by importance. The individual rankings were merged into the synthesized rank ordering of table 7 .

Table 7: Synthesized ranked input from experts on the question 'How do you see the implementation of ethically guidelines?

\begin{tabular}{|l|c|}
\hline & M (STD) \\
\hline $\begin{array}{l}\text { Digital Twins are in fact augmenting human } \\
\text { capabilities. That implies that humans decide }\end{array}$ & $2.22(1.99)$ \\
\hline
\end{tabular}

\begin{tabular}{|l|l|}
\hline $\begin{array}{l}\text { at the end guided by algorithms, medical } \\
\text { professionals, and doctors GP's. }\end{array}$ & \\
\hline $\begin{array}{l}\text { A medical professional should always be in } \\
\text { the loop and a Digital Twin-based solution is } \\
\text { only a tool for a medical professional to aid } \\
\text { in the process of decision making }\end{array}$ & \\
\hline $\begin{array}{l}\text { Complete transparency on the how and why } \\
\text { we use a Digital Twin should give trust to the } \\
\text { patient to use a Digital Twin }\end{array}$ & $3.44(1.57)$ \\
\hline $\begin{array}{l}\text { There will always be a human in the loop - a } \\
\text { medical professional - to ensure that the } \\
\text { advice/treatment inspired by the Digital Twin } \\
\text { is safe for the patient. }\end{array}$ & \\
\hline $\begin{array}{l}\text { Giving the possibility to patient to decide } \\
\text { which data could be added to the Digital } \\
\text { Twin. Patient is to decide whether or not to } \\
\text { use Digital Twin for a specific application. } \\
\text { Patient could stop usage of Digital Twin at } \\
\text { any time. }\end{array}$ & $4.67(1.70)$ \\
\hline $\begin{array}{l}\text { A patient should always accept that } \\
\text { whatever data has been put in by him/her } \\
\text { this data will be anonymized and used for } \\
\text { the good of the crowd. (Like a doctor today, } \\
\text { uses all her/his insights of her/his patients to } \\
\text { finetune to her/his other patients) }\end{array}$ & \\
\hline $\begin{array}{l}\text { Focus on educational aspects - explain } \\
\text { citizens what 'personalised medicine' even } \\
\text { means - Based on that we can engage } \\
\text { people to start sharing personal data useful } \\
\text { to build a DT }\end{array}$ & 5.44 (2.11) \\
\hline
\end{tabular}

We applied a Kendall W coefficient of concordance to measure the agreement and consensus, in this case the agreement was very low, $W=0,276, p$ value $=0,021$.

\subsection{Implementation list Top 3 ranked}

Table 8: Ranked top 3 on the question 'How do you see the implementation of ethically guidelines?

\begin{tabular}{|l|c|}
\hline & M (STD) \\
\hline $\begin{array}{l}\text { Digital Twins are in fact augmenting human } \\
\text { capabilities. That implies that humans decide } \\
\text { at the end guided by algorithms, medical } \\
\text { professionals and doctors GP's. }\end{array}$ & \\
\hline $\begin{array}{l}\text { A medical professional should always be in } \\
\text { the loop and a Digital Twin-based solution is } \\
\text { only a tool for a medical professional to aid in } \\
\text { the process of decision making }\end{array}$ & $3.33(1.76)$ \\
\hline $\begin{array}{l}\text { Complete transparency on the how and why } \\
\text { we use a Digital Twin should give trust to the } \\
\text { patient to use a Digital Twin }\end{array}$ & $3.44(1.57)$ \\
\hline
\end{tabular}

\subsection{Implementation list Top 3 rated according to importance}

Table 9: Rated top 3 on the Question, 'How do you see the implementation of ethical guidelines? Likert scale (1Strongly disagree - 7- Strongly agree)

\begin{tabular}{|l|c|}
\hline & M(STD) \\
\hline $\begin{array}{l}\text { Digital Twins are in fact augmenting human } \\
\text { capabilities. That implies humans decide at } \\
\text { the end }\end{array}$ & $6.33(1.56)$ \\
\hline
\end{tabular}


\begin{tabular}{|l|l|}
\hline Complete transparency on how and why we & $6.22(0.79)$
\end{tabular} use a Digital Twin should give trust to the patient to use a Digital Twin.

A medical professional should always be in 6.11 (1.73) the loop. A Digital Twin-based solution is only a tool for a medical professional to aid in the process of decision making.

The notion that Digital Twins augment human beings implies that humans/patients ultimately are the ones making decisions regarding which routes to traverse in a given medical scenario. With this notion of augmenting people's lives, experts agreed that a complete transparency is needed as to the how and why decisions are made so that a Digital Twin could be trusted by patients. A quote on this matter from one of the experts ' $1 / \mathrm{Al}$ at the service of the individual, where it should help in optimizing healthcare for that specific person, based on the available data of that individual mixed with general data available from similar cases/persons; and 2/ $\mathrm{Al}$ at the service of society, where all data is anonymized and helps to finetune or optimize advice or support for several individuals, stakeholders or for society overall. This difference in data collection and usage should be made explicit from the start. The individual should have the decision power in which personal data and/or context is introduced, should be able to simulate how different versions of that data has an impact on the outcome (in order to finetune his/her input), and should have the decision power how the advice is being implemented in his/her own personal case (in line with how a patient decides to follow or not the advice from his/her doctor)'.

Research shows that ethics in Digital Twins combined with Al applications are extremely important especially in a healthcare environment; not only the privacy of the patient should be protected, but patients should always give their consent in using the data. Furthermore, the robustness of the technology should get great attention in terms of hacks and viruses. Guided by a medical professional to help and guide the patient towards the best outcome for his or her treatment (Barricelli, 2019), (Rasheed, 2020), (Bruynseels, 2018), (AI HLEG, 2019)

\section{DISCUSSION}

With this paper we set out to obtain a consensus view among experts regarding the materialisation, expectation, and the implementation of Digital Twins in healthcare. We worked together with experts who guide and stimulate start-ups in digital healthcare in the Belgian health industry and, more specifically, the futurist and healthcare start-up scene. We choose to look at the definition of a Digital Twin where we adopt the definitions of Grieves, more specifically at a Digital Twin model where the data flows automatically between a physical object and a digital object in two directions. In such a combination, the digital object might also act as controlling instance of the physical object. Furthermore, we also looked at the 'lightweight version of a virtual model' as an enabler for isolated clinical trials or precision medicine. Digital Twins in healthcare are still in early stage, yet it's a technology that moves fast in certain areas of healthcare. In our findings we can categorize them as important for the healthcare industry, the patients and society as a whole. As experts in this study are active in a diverse range of different aspects of digital transformation in healthcare, a wider perspective on the notion of a Digital Twin has been accessed. This is extremely important as there are a variety of different stakeholders in a Digital Twin process. These different stakeholders will need to collaborate and align their efforts to realize a Digital Twin. This multidisciplinary collaboration is equally important if not more than the technical challenges that are there (Fuller, 2020).

The Delphi study helped to reach a consensus quite rapidly. When experts ranked their input on the materialisation and implementation, the ranking agreement was low but significant. However, in a second round, when rating the top 3 there was a high agreement on the top 3 topics. As mentioned, each expert considering the materialisation, expectation, and implementation of Digital Twin with respect to their own domain, they held very diverse views and ideas about it. Another explanation could be that for current implementations of Digital Twins are premature and yet far from a complete implementation.

The materialisation of a Digital Twin is dependent on data sets that are generated by the healthcare industry in the broad sense of this term. This means that private companies gather data through commercialization of devices or mobile applications of all sorts to measure the health status of the individuals as individuals gather that information either voluntarily or pushed (Lupton D. , 2014). Through IOT services individuals also measure certain aspects of their environment and give way to the smart home. Within all this data, standards and interoperability of all these silos become extremely important as one also needs to create context around the data to fulfill the promise of accurate support decision making process. (Malakuti, 2018). In this study experts agreed on three main constructions: first, Digital Twin as a facilitator towards preventive healthcare, this finding is a common given in the literature on Digital Twins in healthcare in general (Fuller, 2020) (Rasheed, 2020) (Rivera, 2019). Second, experts see applications in Intensive Care Unit (ICU), a controlled lab environment where medical professionals can follow patients more accurately following certain parameters linked to any given 
patient. As a last, the construction of trial and error, where a Digital Twin could be operating as a test environment instead of operating and doing trial and error directly on patients, this notion leads way to personalised medicine and human centred patient care, where personalised medicine is tailoring medical treatments based on biomarkers and genetic information of a patient, while centred patient care is about a holistic view of a patient's lifestyle, 'considering the individual behind the patient' (El-Alti, 2019).

As mentioned, earlier healthcare applications entering the market are already making the first steps towards Digital Twins, as for example, Fibircheck and Epicare@home. Experts agreed on their expectation that through a trial-and-error process, a Digital Twin could give more insight in the remedial process of a certain pathology with a given patient. Digital Twins can give information on the past using historical data, the state of now as they are living data objects and always up to date. Moreover, through deep learning algorithms Digital Twins can predict or forecast a given situation for an individual. In addition, experts also agreed that given the ability of deep learning algorithms, Digital Twins can create a context around the data to improve upon the accuracy of health assessment and support decision making.

Experts also had high expectations regarding the application of a Digital Twin at a macro level, for example, to give an overview of the health status of a population - society as whole of a certain neighbourhood, a region, or a nation. In our introduction we mentioned the dangers of creating new digital divides, an elite class would benefit from Digital Twins. This emphasizes the need to 'democratize technologies', creating policies and regulations that are inclusive rather than being exclusive. (Rasheed, 2020) (Fukuyama, 2002). Our panel agreed that 'Digital Twins should be seen as augmenting human beings, with humans/patients ultimately determining which decisions are made within the process. The autonomy and agency of patients in using a Digital Twin is an important aspect in the implementation of Digital Twins in healthcare (Bartneck, 2020). This implies that there should always be a human in the loop. 'A Digital Twin-based solution is only a tool for aiding a medical professional in their decision making' notes one of the experts. Experts argued for, 'complete transparency on how and why we use a Digital Twin should give trust to the patient to use a Digital Twin'. When considering all the input given by the experts for this paper, one can conclude that Digital Twins hold some valuable promise to improve prevention and personalised medicine, providing more accurate and detailed views on a given individual/patient to support more accurate decision making in complete transparency, in collaboration and guided by a medical professional.

\section{LIMITATIONS}

This study was conducted in Belgium and the experts identified are representing views relevant in the local health system and industrial context. The questions we raised may be answered differently in countries with a more dominant private sector in healthcare, or with less stringent privacy regulations than the European Union. Further, the representation of industry in our study lacked the representation of pioneering companies, like Fibricheck or Byteflies mentioned above, or world leading industries in healthcare technology which can have a radically different perspective as to what is feasible or desirable.

Regarding the Delphi method as such, it was successful in reaching a consensus view. While experts disagreed at the first round, consensus could be reached within 2 of the 3 iterations. One of the reasons for the divergent views could be that the experts depart from their own domain of expertise and consider the needs of different sectors.

Future research should expand on topics that this study did not examine in depth, such as the ethical aspects of Digital Twins and the user (non-expert) perspective on these developments.

\section{CONCLUSION}

In this study we used the Delphi research method to get a broader view and consensus on the prospects of Digital Twins in healthcare. The main findings and conclusions of this study were that experts view a Digital Twin as a facilitator of preventive healthcare, a testing environment in an ICU controlled environment, where certain parameters of a patient are tracked, resulting in more accurately follow up on a given patient. The controlled environment also gives the ability to have a trial-and-error environment, that leads to personalised medicine and/or centred patient care. In addition, the expectations of a Digital Twin are seen as a way to get insight in remedial medical processes, creating context around the data that is available and giving oversight on the health status of a given population. Furthermore, experts see Digital Twins as a tool supporting decision making by medical professionals in complete transparency. Further research is needed on user perspectives and ethical aspects of Digital Twins in healthcare. 


\section{REFERENCES}

AI HLEG, (2019). Ethics Guidelines For Trustworthy Al.https://ec.europa.eu/digital-singlemarket/en/news/ethics-guidelines-trustworthy-ai.

Bagaria, N. (2020). Health 4.0: Digital Twins for Health and Well-Being. pp. 143-152.

Barrett, M. A. (2013, September). Big Data and Disease Prevention: From Quantified Self to Quantified Communities. Big Data, pp. 168-175.

Barricelli, B. R. (2019). A Survey on Digital Twin: Definitions, Characteristics, Applications, and Design Implications. IEEE Xplore, 7, pp. 167653167671.

Bartneck, C. (2020). An Introduction to Ethics in Robotics and Al. SpringerBriefs in Ethics.

Bruynseels, K. (2018). Digital Twins in Health Care: Ethical Implications of an Emerging Engineering Paradigm. Frontiers in Genetics, 31.

Byteflies.(n.d.).Retrieved

from https://www.byteflies.com/

De Maeyer, C. (2020). Are Digital Twins becoming our Personal (predictive) Advisors? 'Our Digital Mirror of Who We Were, Who We Are and Who We Will Become'. $\mathrm{HCl}$ International 2020. 12208. Copenhagen: Gao Q., Zhou J. (eds) Human Aspects of IT for the Aged Population. Healthy and Active Aging. HCll 2020. Lecture Notes in Computer Science. Springer, Cham.

El-Alti, L. (2019). Person Centered Care and Personalized Medicine: Irreconcilable Opposites or Potential Companions? Health Care Anal, pp. 45-59.

Elayan, H. (2021). Digital twin for intelligent context-aware iot healthcare systems. leee Internet of Things Journal.

Etzkowitz, H. (2017). The Triple Helix: UniversityIndustry-Government Innovation and Entrepreneurship (2nd ed.). Routledge.

Fibricheck.(n.d.).Retrieved from https://www.fibricheck.com/

Fukuyama, F. (2002). Our Posthuman Future: Consequences of the Biotechnology Revolution. Published by Farrar, Straus and Giroux. Macmillan.

Fuller, A. F. (2020). Digital Twin: Enabling Technology, Challenges and Open Research. IEEE Access, 8, pp. 108952-108971.

Gordon, T. J. (1994). The Delphi Method.

Grieves, M. (2014, January 3). Digital Twin: Manufacturing Excellence through Virtual Factory Replication. USA.
Grieves, M. (2017). Digital Twin: Mitigating Unpredictable, Undesirable Emergent Behavior in Complex Systems. Kahlen FJ., Flumerfelt S., Alves A. (eds) Transdisciplinary Perspectives on Complex Systems.

Healthouse, Retrieved from https://www.healthhouse.be/en/

Helmer, O. (1950-60). Retrieved from https://www.rand.org/

Justice, A. (n.d.). Algoritmic Justice League: Unmasking Al harms and Biases. Retrieved from https://www.ajl.org/

Kritzinger, W. (2018). Digital Twin in manufacturing: A categorical literature review and classification. IFAC-PapersOnLine, 51(11), pp. 1016-1022.

Lakki, H. (2019). Prototyping a Digital Twin for Real Time Remote Control Over Mobile Networks: Application of Remote Surgery. IEEE Access.

Lewis, D. (2021). Contact-Tracing Apps Help to Reduce Covid Infections. Nature.

Lupton, D. (2014). Self-Tracking Modes: Reflexive Self-Monitoring and Data Practices. SSRN Electronic Journal.

Lupton, D. (2019). Data selves, More-than-Human Perspectives. Wiley.

Malakuti, S. (2018). Architectural aspects of digital twins in IloT systems. Proceedings of the 12th European Conference on Software Architecture: Companion Proceedings ECSA '18, Association for Computing Machinery, N (pp. 1-2). ACM Digital Library.

Mullen, P.M., (2003). Delphi:myths and reality, Journal of Health Organization and Management, Vol 17 No1, pp 37-52

O' Neill, C. (2016). Weapons of math destruction. Crown Books.

Persistent. (2020). Digital Twin Whitepaper. Retrieved from https://www.persistent.com/wpcontent/uploads/2020/01/digital-twinswhitepaper.pdf

Rasheed, A. (2020). Digital Twin: Values, Challenges and Enablers From a Modeling Perspective. IEEE Access, 21980-22012.

Renzi, A.B. (2015). Delphi method to explore future scenario possibilities on technology and $\mathrm{HCl}$. Marcus A. (eds) Design, User Experience, and Usability: Design Discourse. Lecture Notes in Computer Science. Springer, Cham.

Rivera, L. F. (2019). Towards continuous monitoring in personalized healthcare through digital twins. Proceedings of the 29th Annual International Conference on Computer Science and Software 
Engineering (CASCON '19) (pp. 329-335). IBM Corp.

Rodríguez, P. (2021). A population-based controlled experiment assessing the epidemiological impact of digital contact tracing. Nat Commun 12, 587.

Saaty, T. (2008). Decision making with the analytic hierarchy process . Int. J. Services Sciences, Vol. 1, No. 1.

Saddik, A. (2018). Digital Twins: The Convergence of Multimedia Technologies. IEEE MultiMedia,, 87-92.

Searl, M. (2010). It is time to talk about people: a human-centered healthcare system. Health Res Policy Syst.

Smith, G. (2016). Surveillance, Data and Embodiment: On the Work of Being Watched. Body \& Society, Vol.22, 108-139.

Schwartz, (2020). Digital Twins and the Emerging Science of Self: Implications for Digital Health Experience Design and "Small" Data. Frontiers in Computer Science, 31.

World Economic Forum. (2020, April 7). Retrieved from What can smart cities tell us about covid19:

https://www.weforum.org/agenda/2020/04/smartcities-technology-coronavirus-covid19/

Yang, C. (2019). Exploring Design Guidelines of Using User-Centered Design in Gamification Development: A Delphi Study. International Journal of Human-Computer Interaction, 11701181. 